\title{
Dependence Study of Optoelectronics Performance on Carefully Differed LiF Thickness in Alq 3 Based OLEDs
}

\author{
Shengxun Su, Changxiao Pan, Xi Luo, Wei Chen, Jiarong Lian* \\ Key Laboratory of Optoelectronic Devices and Systems of Ministry of Education and Guangdong province, \\ Shenzhen University, No.3688, Nanhai Road, Nanshan District, Shenzhen 518060, China \\ Email: ${ }^{*}$ ljr@szu.edu.cn
}

Received 2013

\begin{abstract}
The effect of LiF thickness on the electrical and luminescent characteristics in OLEDs has been studied by carefully varying thickness value range from $0 \mathrm{~nm}$ to $1.2 \mathrm{~nm}$. It's interesting to find that the device with $0.2 \mathrm{~nm}$ LiF layer performs the largest current and comparative lower luminescent efficiency, while the one with $0.6 \mathrm{~nm}$ LiF performs another current peak (lower than that of device with $0.2 \mathrm{~nm}$ LiF layer) but the highest luminescent efficiency in all devices. Here the much enhanced electron injection and destructive efficiency for $0.2 \mathrm{~nm}$ LiF device are understood by the chemical interaction model at cathode interface, while the fairly increased electron injection and much improved efficiency for $0.6 \mathrm{~nm} \mathrm{LiF}$ device would be interpreted by other mechanisms, and LiF plays a protective part in preventing the deposition-induce photoluminescence from quenching by $\mathrm{Al}$ cathode.
\end{abstract}

Keywords: OLEDs; Thickness; LiF; Chemical Interaction; Luminescent Quenching

\section{Introduction}

Since the report of Tang and VanSlyke [1] of multilayer organic light-emitting devices (OLEDs), tremendous efforts have been made to improve the device performance. To improve the performance of OLEDs, carrier injection and transport mechanisms for organic materials have been widely investigated. A famous approach for efficient electron injection into $\mathrm{Alq}_{3}$ was first reported by Hung et al. [2], who used $\mathrm{Al}$ metal together with a thin interlayer of LiF. Although the effects of this layer cathode on electron injection have been well recognized, the role of the LiF electron injection layer (EIL) has long been in dispute [2-4]. A number of mechanisms have been proposed in the literatures, including: (a) the insulating buffer model, which attributes electron injection enhancement to the tunneling effect. The biased LiF layer would take a large electric field because of its excellent insulating property (with wide band gap of $12 \mathrm{eV}$ ), and shift the electronic states of electrode to a higher level thus a more direct electron injection into the lowest unoccupied molecular orbital of the electron transporting material can be obtained [4-6]; (b) Chemical reaction model, in which chemical interaction takes place at the interface of $\mathrm{LiF} / \mathrm{Al}$ or Aluminum 8-hydroxyquinolinate $\left(\mathrm{Alq}_{3}\right) / \mathrm{LiF} / \mathrm{Al}$ [7-9]. The subsequent observed phenomena include the $\mathrm{LiF}$ dissociation and $\mathrm{Alq}_{3}$ anion for-

\footnotetext{
*Corresponding author.
}

mation with Li doping. The XPS results further indicate that this reaction does not occur at $\mathrm{LiF} / \mathrm{Al}$ interface in the absence of $\mathrm{Alq}_{3}$, but in the presence of it [9]; (c) Bang bending model, which makes the band bended to a certain extent, leading it easier for electron to inject into the organic material [10]. The significance of these studies lies in that they each support one of the different categorized models. For example, using a LiF-doped Al composite cathode to replace the conventional layer electrode of $\mathrm{LiF} / \mathrm{Al}$ exhibits the almost identical beneficial effect on the I-V and L-I characteristics, and the enhanced electron injection in devices with a composite cathode can be attributed neither to tunneling through an insulator nor to the band bending at the metal-organic interface [11]. Another study by Wang et al., however, opposed the result and showed that a $\mathrm{Ag} / \mathrm{LiF}(3 \mathrm{~nm})$ cathode can also increase the electron injection by varying the $\mathrm{LiF}$ thickness [12].

In this paper, we have researched the optical and electrical performances dependence of the OLEDs on the thickness of LiF interlayer. Although other researchers have published articles to indicate that different optical properties would be obtained when the LiF thickness changes, the step of LiF thickness change in their researches are much larger than that as we did. In our experiments, it is interesting to find that there are two current peaks when carefully increasing LiF thickness from $0 \mathrm{~nm}$ to $1.2 \mathrm{~nm}$, which is different with that of others. And, a conclusion can be safely drawn that different 
mecha- nisms for enhanced electron injection would play a part when LiF thickness changes.

\section{Experiment}

In our experiments, the structures of reference OLEDs are consist of indium tin oxide(ITO) substrates as anodes, molybdenum oxide $\left(\mathrm{MoO}_{3}\right)$ as hole injecting layers, NPB as hole transport layers, $\mathrm{Alq}_{3}$ as electron transport layers, $\mathrm{LiF}$ as electron injection layers and $\mathrm{Al}$ as cathodes. The sequences of each layer are as follows: glass substrate/ ITO/ $\mathrm{MoO}_{3}(10 \mathrm{~nm}) / \mathrm{NPB}(40 \mathrm{~nm}) / \mathrm{Alq}_{3}(60 \mathrm{~nm}) / \mathrm{LiF}$ $(\mathrm{Xnm}) / \mathrm{Al}(100 \mathrm{~nm})$, of which chooses $\mathrm{X}$ value between $0 \mathrm{~nm}$ to $1.2 \mathrm{~nm}$ with an increasing step of $0.1 \mathrm{~nm}$. The ITO/glasses substrates were used after routinely clean process without oxidization treatment [13]. The devices were prepared by thermal evaporation from resistively heated crucibles in three connected vacuum chambers. In one of the chambers, organic films of $\mathrm{Alq}_{3}$ and NPB are deposited at a pressure of $2 \times 10^{-4} \mathrm{p}_{\mathrm{a}}$ at a deposition rate of $0.1 \mathrm{~nm} / \mathrm{s}, \mathrm{MoO}_{3}$ and $\mathrm{LiF}$ layers were deposited in the adjacent evaporation chamber at a pressure of $4 \times 10^{-4} \mathrm{p}_{\mathrm{a}}$, at rates of $0.03 \mathrm{~nm} / \mathrm{s}$ and $0.01 \mathrm{~nm} / \mathrm{s}$, and metal $\mathrm{Al}$ electrodes were deposited at a pressure of $8 \times 10^{-4} \mathrm{pa}$, at a rate of $1.5 \mathrm{~nm} / \mathrm{s}$. The rates of evaporation and thicknesses of the film were monitored via Model TDM-200 measure unit produced by Weitai Company. All samples were rotated at uniform velocity during deposition so as to guarantee the homogeneous films.

The current density (J) - luminance (L) - voltage (V) characteristics of the devices were measured by a Keithley SMU 2400 source-measure unit and BM-8 multifunction radiant measurement meter in ambient condition after device fabrication. Photoluminescence quenching experimental was tested via LS 45 Fluorescence Spectrometer (PerkinElmer).

\section{Results and Discussion}

Figure 1 displays the typical current characteristics of the OLEDs mentioned above, and the specific current values at given voltages are also plotted in the insert of Figure 1. As is shown in Figure 1, all devices with a LiF interlayer perform obviously larger current than that of standard devices, illustrating that all LiF layers with thickness less than $1.2 \mathrm{~nm}$ improve electron injection effectively, which is consistent with the reference reports [2]. However, we can also find that devices show different current performances with the LiF thickness change. To show the changing law of the current more clearly, we compared the current density at given voltage $12 \mathrm{~V}, 10 \mathrm{~V}$ and $8 \mathrm{~V}$, respectively. As is shown in insert, all three curves at the given voltage have the same profile. Here the one at $12 \mathrm{~V}$ is chosen as an example. When $\mathrm{LiF}$ thick- ness increases from $0 \mathrm{~nm}$ to $0.2 \mathrm{~nm}$, the current density in- creases sharply and reaches its maximal value $\left(678 \mathrm{~mA} / \mathrm{cm}^{2}\right)$ at $0.2 \mathrm{~nm}$. Then, it decreases rapidly when go on increasing $\mathrm{LiF}$ thickness from $0.2 \mathrm{~nm}$ to $0.4 \mathrm{~nm}$. While further increasing $\mathrm{LiF}$ thickness from $0.4 \mathrm{~nm}$ to $0.6 \mathrm{~nm}$, current density of the device increases again and reaches another maximal value $\left(490 \mathrm{~mA} / \mathrm{cm}^{2}\right)$ at $0.6 \mathrm{~nm}$. Lastly, the current density decreases slowly while LiF thickness further increases to $1.2 \mathrm{~nm}$. Therefore, two maximal values of current density can be found with the increase of $\mathrm{LiF}$ thickness. None of the existing injection mechanism, including chemical reaction model, band bending, tunneling model etc. can explain the two-maximal-value phenomenon independently. Thus, a hypothesis can be easily drawn that there may be more than one electron injection mechanisms are needed to explain the two-maximal-value phenomenon.

In order to further investigate the influence of $\mathrm{LiF}$ thickness on the luminescent characteristics of devices, the current efficiency curves in devices are also plotted in Figure 2. It can be seen that the standard device without LiF layer, which performs the lowest current efficiency, exhibits the maximal value of only $1.5 \mathrm{~cd} / \mathrm{A}$. After adding a LiF interlayer, luminous efficiency of all the devices are improved obviously, which probably because the

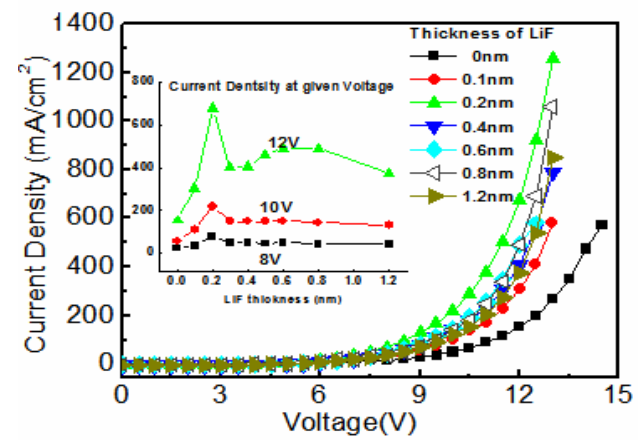

Figure 1. the current-voltage and current-LiF thickness characteristic for OLEDs with different thickness of LiF layer between the $\mathrm{Al}$ cathode and light-emitting-layer.

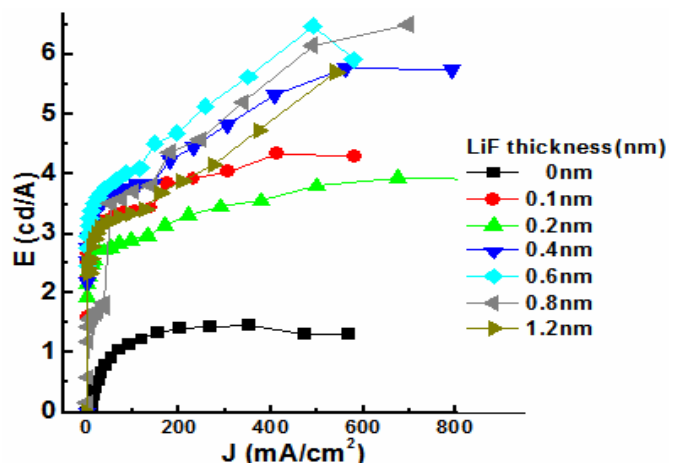

Figure 2. The EL efficiency-current characteristic for OLEDs with different thickness of $\mathrm{LiF}$ layer between $\mathrm{Al}$ cathode and $\mathbf{A l q}_{3}$.

improved electron injection making the carrier more 
balance in the emitting layer. As we all known, not only the injection barrier of the hole is much lower than that of the electron, but also the mobility of the hole transporting layer is far greater than that of electron, thus the device is in a hole-rich status [14]. Therefore, devices with LiF layer help to improve the electron injection, making carriers of the light-emitting layer more balanced and reducing the hole-current leakage of devices, then the luminous efficiency is improved. However, it also shows that not all the devices follow the law that the more balanced the carriers are, the higher luminous efficiencies are performed. For example, the current of device reaches its maximal value when the $\mathrm{LiF}$ layer is 0.2 $\mathrm{nm}$ but its luminous efficiency is only $3.9 \mathrm{~cd} / \mathrm{A}$, which is not the maximal value and is even lower than that of other devices with LiF interlayer. As for comparison, the device with $\mathrm{LiF}$ thickness of $0.6 \mathrm{~nm}$, has the highest maximal efficiency of $6.5 \mathrm{~cd} / \mathrm{A}$. Therefore, it indicates that a large part of exciton in light emitting layer must be quenched when LiF thickness is $0.2 \mathrm{~nm}$.

To confirm the quenching phenomenon in the light emitting layer, we have further conducted photoluminescence (PL) experiment, which compares the PL intensity of four kinds of films with structures of $\mathrm{Alq}_{3}(30 \mathrm{~nm})$, $\mathrm{Alq}_{3}(30 \mathrm{~nm}) / \mathrm{Al}(2 \mathrm{~nm}), \mathrm{Alq}_{3}(30 \mathrm{~nm}) / \mathrm{LiF}(0.2 \mathrm{~nm}) / \mathrm{Al}(2$ $\mathrm{nm})$ and $\mathrm{Alq}_{3}(30 \mathrm{~nm}) / \mathrm{LiF}(0.7 \mathrm{~nm}) \mathrm{Al}(2 \mathrm{~nm})$. As is shown in Figure 3, the largest PL intensity of 629 A.U. at a wave- length of $505 \mathrm{~nm}$ has performed in the neat $\mathrm{Alq}_{3}$ film. After evaporating a $2 \mathrm{~nm} \mathrm{Al}$ on the $\mathrm{Alq}_{3}$ layer, the PL intensity of the light-emitting layer reduced to 390 A.U. and about $38 \%$ of total intensity is lost, which reveals that $\mathrm{Al}$ atoms have a severe quenching effect on the light-emitting layer. When inserting a $0.7 \mathrm{~nm} \mathrm{LiF}$ layer, the PL intensity is increased to 491 A.U., which indicates that the quenching effect of $\mathrm{Al}$ has been prevented obviously and the LiF layer plays the protective function. In

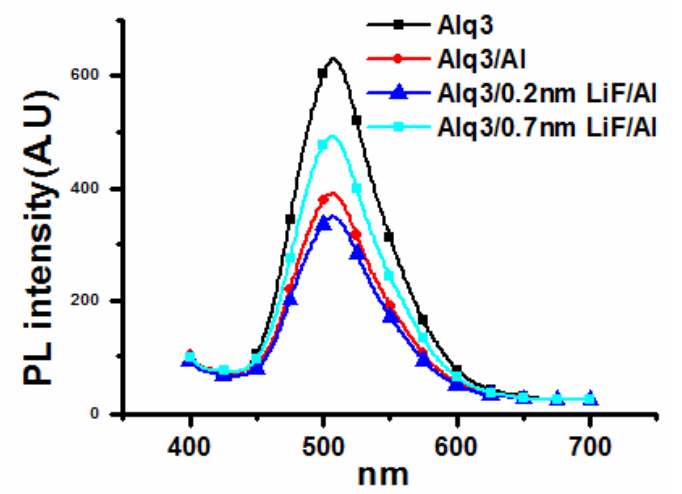

Figure 3. The photoluminescence (PL) curves for the films of $\mathrm{Alq}_{3}, \mathrm{Alq}_{3} / \mathrm{Al}, \mathrm{Alq}_{3} / 0.2 \mathrm{~nm} \mathrm{LiF} / \mathrm{Al}$ and $\mathrm{Alq}_{3} / 0.2 \mathrm{~nm} \mathrm{LiF} / \mathrm{Al}$, which the thickness of $\mathrm{Alq}_{3}$ and $\mathrm{Al}$ is $30 \mathrm{~nm}$ and $2 \mathrm{~nm}$, respectively.

fact, quenching effect of $\mathrm{Al}$ has been almost prevented by the $0.7 \mathrm{~nm} \mathrm{LiF}$ layer, because the $\mathrm{Alq}_{3} / \mathrm{LiF}(0.7 \mathrm{~nm})$ film plays the comparable PL intensity (489 A.U) with that of $\mathrm{Alq}_{3} / \mathrm{LiF}(0.7 \mathrm{~nm}) / \mathrm{Al}(2 \mathrm{~nm})$, of which the further deposition of $\mathrm{Al}$ layer takes near no effect on PL intensity. On the contrast, when inserting a $0.2 \mathrm{~nm} \mathrm{LiF}$ layer between $\mathrm{Alq}_{3}$ and $\mathrm{Al}$, the PL intensity is only 348 A.U., which is even lower than that of $\mathrm{Alq}_{3}(30 \mathrm{~nm}) / \mathrm{Al}(2 \mathrm{~nm})$. Given that both of the $\mathrm{LiF}$ layers with thickness value of $0.2 \mathrm{~nm}$ and $0.7 \mathrm{~nm}$ have the same chemical states, the LiF layer with $0.2 \mathrm{~nm}$ thickness would prevent the diffusion of the $\mathrm{Al}$ atom and reduce the PL quenching effect in a certain extent as the one with $0.7 \mathrm{~nm}$ thickness does, thus improve the PL intensity, which is opposite to the experimental results. Therefore a different chemical state can be deduced for $\mathrm{LiF}$ layer at $\mathrm{Alq}_{3} / \mathrm{Al}$ interface when its thickness changes from $0.7 \mathrm{~nm}$ to $0.2 \mathrm{~nm}$, another quenching factor may also be introduced into $\mathrm{Alq}_{3}$ layer. Here the chemical reaction mechanism is the most probable explanation for the lowest $\mathrm{PL}$ intensity in $\mathrm{Alq}_{3}$ (30 $\mathrm{nm}) / \mathrm{LiF}(0.2 \mathrm{~nm}) / \mathrm{Al}(2 \mathrm{~nm})$ film. According to the chemical reaction model, $\mathrm{Li}$ was reported being released when the chemical reaction took place at the ternary interface of $\mathrm{Alq}_{3} / \mathrm{LiF} / \mathrm{Al}$, and diffusing into $\mathrm{Alq}_{3}$ layer, which would exert certainly destructive effect on luminescent characteristics [15].

\section{Conclusions}

In summary, we have carefully changed the thickness of LiF electron injection layer and studied the optical and electrical characteristics changes of OLEDs. Two peaks in current density were founded by differing $\mathrm{LiF}$ thickness from $0 \mathrm{~nm}$ to $1.2 \mathrm{~nm}$. The device with $0.2 \mathrm{~nm} \mathrm{LiF}$ layer performs the largest current and comparative lower luminescent efficiency, while the one with $0.6 \mathrm{~nm} \mathrm{LiF}$ performs another current peak (lower than that of device with $0.2 \mathrm{~nm}$ LiF layer) but the highest luminescent efficiency in all devices. Here the much enhanced electron injection and destructive efficiency for device with a 0.2 $\mathrm{nm}$ LiF layer are understood by the chemical interaction model at cathode interface, while the fairly increased electron injection and much improved efficiency in the one with a $0.6 \mathrm{~nm} \mathrm{LiF}$ layer, would be interpreted by the other mechanisms, and LiF taking a protective function in preventing the deposition-induce photoluminescence from quenching by Al cathode.

\section{Acknowledgements}

This work was supported by Natural Science Foundation of China (Grand No. 61106094 and 20972097), Natural Science Foundation of Guangdong Province (Grand No. S2012020011003), Educational Commission of Guangdong Province (Grant No. LYM11111), Shenzhen Science Foundation (Grant No. JC201005280458A). 


\section{REFERENCES}

[1] C. W. Tang and S. A. VanSlyke, "Organic Electroluminescent Diodes,” Applied Physics Letters, Vol. 51, No.12, 1987, pp. 913-915. doi: 10.1063/1.98799

[2] L. S. Hung, C. W. Tang and M. G. Mason, "Enhanced Electron Injection in Organic Electroluminescence Devices Using an $\mathrm{Al} / \mathrm{LiF}$ Electrode,” Applied Physics Letters, Vol. 70, No. 5, 1997, pp. 152-154. doi: 10.1063/1.118344

[3] Y. Takahiro, Y. Daisuke, I. Eisuke, I. Hisao, O. Yukio and S. Kazuhiko, "Energy Level Alignment at $\mathrm{Alq}_{3} / \mathrm{LiF} / \mathrm{Al}$ Interfaces Studied by Electron Pectroscopies: Island Growth of LiF and Size- Dependence of the Electronic Structures," Journal of Applied Physics, Vol. 42, No. 6A, 2003, pp. 3666-3675.doi: 10.1143/JJAP.42.3666

[4] G. E. Jabbour, Y. Kawabe, S. E. Shaheen, J. F. Wang and M. M. Morrell, "Highly Efficient and Bright Organic Electroluminescent Devices with An Aluminum Cathode," Applied Physics Letters, Vol. 71, No. 13, 1997, pp. 1762-1764. doi:10.1063/1.119392

[5] R. Schlaf, B. A. Parkinson, P. A. Lee, K. W. Nebesny, G. Jabbour, "Photoemission Spectroscopy of LiF Coated Al and Pt electrodes," Journal of Applied Physics, Vol. 84, No. 12, 1998, pp. 6729-6736. doi: 10.1063/1.369000

[6] Y. E. Kim, H. Park and J. J. Kim, "Enhanced Quantum Efficiency in Polymer Electroluminescence Devices by Inserting A Tunneling Barrier Formed by Langmuir-Blodgett Films,” Applied Physics Letters, Vol. 69, No. 5, 1996, pp. 599-601. doi: 10.1063/1.117919

[7] M. G. Mason, C. W. Tang, L. S. Hung, P. Raychaudhuri and J. Madathil, "Interfacial Chemistry of Alq3 and LiF with Reactive Metals,” Journal of Applied Physics, Vol. 89, No. 5, 2001, pp. 2756-2765. doi: $10.1063 / 1.1324681$

[8] H. Heil, J. Steiger, S. Karg, M. Gastel and H. Ortner, "Mechanisms of Injection Enhancement in Organic Light- emitting Diodes through An Al/LiF Electrode,” Journal of Applied Physics, Vol. 89, No. 1, 2001, pp. 420-424. doi: 10.1063/1.1331651

[9] Z. T. Xie, W. H. Zhang, B. F. Ding, X. D. Gao and Y. T. You, "Interfacial Reactions at $\mathrm{Al} / \mathrm{LiF}$ and $\mathrm{LiF} / \mathrm{Al}$," $\mathrm{Ap}$ plied Physics Letters, Vol. 94, No.6, 2009, pp. 063302-01- 063302-03. doi: 10.1063/1.3077167

[10] K. Ihm, T.-H. Kang, K.-J. Kim, C.-C. Hwang and Y.-J. Park, "Band Bending of $\mathrm{LiF} / \mathrm{Alq}_{3}$ Interface in Organic Light-Emitting Diodes,” Applied Physics Letters, Vol. 83, No. 14, 2003, pp. 2949-2952. doi: 10.1063/1.1616977

[11] L. S. Hung, R. Q. Zhang, P. He and M. G. Mason, “Contact Formation of LiF/Al Cathodes in $\mathrm{Alq}_{3}$-Based Organic Light-Emitting Diodes,” Journal of Physics D: AppliedPhysics, Vol. 35, No. 2, 2002, pp. 103-107. doi: 10.1088/0022-3727/35/2/302

[12] X. J. Wang, J. M. Zhao, Y. C. Zhou, X. Z. Wang and S. T. Zhang, "Enhancement of Electron Injection in Organic Light-Emitting Devices Using An Ag/LiF Cathode," Journal of Applied Physics, Vol. 95, No. 7, 2004, pp. 3828-3830. doi: 10.1063/1.1655676

[13] J. R. Lian, Y. W. Liu, F. F. Niu and P. J. Zeng, "Improved Electron Injection of OLEDs with A Thin PBD Layer At $\mathrm{Alq}_{3} / \mathrm{Cs}_{2} \mathrm{CO}_{3}$ Interface," Applied Surface Science, Vol. 257, No. 10, 2011, pp. 4608-4611. doi:10.1016/j.apsusc.2010.12.092

[14] G. E. Jabbour, J.-F. Wang and N. Peyghambarian, "High-Efficiency Organic Electrophosphorescent Devices through Balance of Charge Injection,” Applied Physics Letters, Vol. 80, No. 11, 2002, pp. 2026-2028. doi: 10.1063/1.1458687

[15] J. J. Kido and Toshio Matsumoto, "Bright Organic Electroluminescent Devices Having A Metal-Doped Electron Injecting Layer,” Applied Physics Letters, Vol. 73, No. 20, 1998, pp. 2866-2868. doi: 10.1063/1.122612 